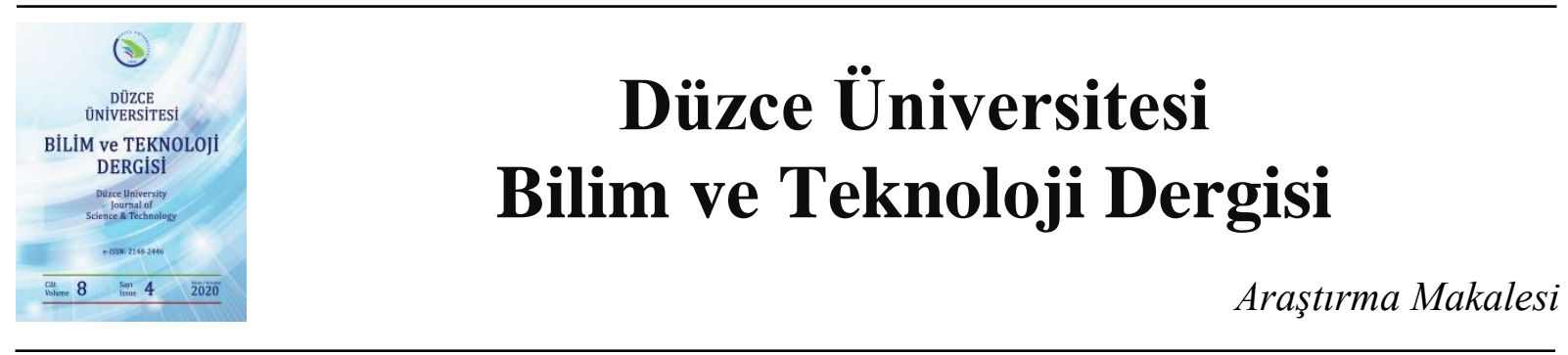

\section{Parkinson Hastalarının Tespitinde Karınca Koloni Algoritması ile Seçilen Özniteliklerin Performansa Etkisi}

\author{
(1D)Ali NARİN ${ }^{\mathrm{a}, *}$ \\ ${ }^{a}$ Elektrik Elektronik Mühendisliği Bölümü, Mühendislik Fakültesi, Zonguldak Bülent Ecevit Üniversitesi, \\ Zonguldak, TÜRKIYYE \\ * Sorumlu yazarin e-posta adresi: alinarin@beun.edu.tr \\ DOI: 10.29130/dubited.650958
}

\begin{abstract}
ÖZET
Nerodejeneratif bir hastalık olan Parkinson, dopamin üreten hücrelerin zamanla azalması sonucunda ortaya çıkar. $\mathrm{Bu}$ azalma yaşa bağlı olarak değiş̧ir. Dünya nüfusunun yaşlandığ 1 gerçeğine göre bakıldığında bu hastalığın ilerleyen yıllarda daha da artacağı söylenebilir. Parkinson hastalığının tanısı oldukça uzun süreli bir iştir. Kesin bir tanı mekanizması olamamakla birlikte çoğunlukla hasta uzun bir süre takibe alınır ve sonrasında Parkinson hastalı̆̆ına tanı konulabilir. Bu çalışmada, nörologlara yardımcı bir tanı mekanizması önerilmiştir. Ses verileri yardımıyla Parkinson hastalığına sahip olanlar otomatik olarak tespit edilmiştir. Elde edilen özniteliklere min-max normalizasyon işlemi uygulanıp, karınca koloni algoritması (KKA) ile özniteliklerin seçilmesi işlemi ile tespit başarımlarının arttırılması amaçlanmıştır. Hem normalize edilmiş hem KKA ile seçilmiş özniteliklerin başarımı arttırdığı gösterilmiştir. Destek vektör makinalarının ikinci dereceden fonksiyonları ve KKA ile seçilen 30 adet öznitelik ile $\% 87,5$ doğruluk, $\% 89,2$ duyarll1ık, $\% 85,8$ özgüllü̈ ve $\% 89,2$ hassaslık ile en yüksek başarım değerleri elde edilmiştir.
\end{abstract}

Anahtar Kelimeler: Parkinson, min-max nomalizasyon, karınca koloni optimizasyon algoritmasl, öznitelik seçimi.

\section{Effect of Features Selected by Ant Colony Algorithm in Performance of Parkinson's Patients}

\begin{abstract}
Parkinson is a neurodegenerative disease, occurs when dopamine-producing cells diminish over time. This reduction varies depending on age. Looking at the fact that the world's population is aging, it can be stated that this disease will increase in the following years. The diagnosis of Parkinson's disease is a long-term task. Although there is no definite diagnosis mechanism, the patient is usually followed up for a long time and then the disease can be diagnosed. In this study, a diagnostic mechanism is proposed to assist neurologists. Parkinson's disease is detected automatically with the help of voice data. The min-max normalization process is applied to the obtained features and the purpose of this study is to increase the detection performance by selecting the features with ant colony algorithm (ACO). It has been shown that both normalized data and ACOselected features increase performance. The highest performance values are obtained with $87.5 \%$ accuracy, $89.2 \%$ sensitivity, $85.8 \%$ specificity and $89.2 \%$ precision with the polynomial functions of the support vector machines and 30 features selected by ACO.
\end{abstract}

Keywords: Parkinson, min-max normalization, ant colony optimization algorithm, feature selection 


\section{GIRIS}

Beyindeki dopamin salgısı, kişilerin el, kol, konuşma vb. hareketlerini sağlıklı yapabilmesi için beynin bölgeleri arasında köprü görevi görmektedir. Bu maddeyi üreten hücrelerin zamanla azalması sonucunda meydana çıkan Parkinson hastalığı nörodejeneratif bir hastalıktır [1-3]. Nörodejeneratif hastalıklar içerisinde Alzheimer hastalığından sonra en yaygın karşılaşılan bir türdür [4]. Bu hastalık halk arasında titrek felç olarak da adlandırılır. Parkinson hastalığı yavaş ilerlemesi ile bilinir. Özellikle, 40-70 yaşlarında sıklıkla görülebilmekle beraber genellikle yaşlılarda görülür. İstatistiksel verilere bakıldığında, Amerika da toplam 1 milyon Parkinson hastası olduğu bilinirken, her yıl yaklaşık 60 bin kişiye Parkinson tanısı konulduğu ifade edilmektedir [5]. Avrupa da ise bu sayı toplamda 1,2 milyonu bulmaktadır [6]. Ülkemizde ise toplamda yaklaşık 150 bin Parkinson hastası olduğu bildiriliyor [7]. Tüm bu veriler 1 şığı altında, tüm dünyada yaşlı nüfusunun artıyor olduğu gerçeğiyle de bakarsak, bu hastalığın gelecek yıllarda çok daha fazla sayıya ulaşacağı öngörülebilmektedir.

Parkinson hastalığının belirtileri diğer hastalıklarla karıştırılmakla beraber, çoğunlukla günlük hareketlerde zorlanma ve yavaşlama, dinlenme esnasında el ve kollarda titreme, kaslarda sertleşmenin meydana gelmesi, reflekslerde bozulmalar gibi belirtilerin yanı sira unutkanlık, koku almalarda zayıflama, depresyon hissi ve uyku bozuklukları gibi motor olmayan belirtiler de baş gösterebilir $[7,8]$.

Tüm bu belirtilerle birlikte Parkinson hastalarının yaklaşık \% 90'nında konuşma bozukluğunun meydana geldiği ifade edilmektedir [9]. Burada, sakin ve tekdüze bir konuşma, ses tonlamalarında monotonluk ve yumuşaklık, konuşmalarında anlaşılmazlık gibi belirtilerden bahsedilmektedir [10].

Parkinson hastalığının kesin ve net bir teşhis yöntemi şu an için bulunmamaktadır [11]. Ayrıca bir görüntüleme ve tahlil sonucunu ile kolay tanı konulamaz. Genellikle teşhis edilirken hasta uzun bir süre izlenir. Hastanın nörolojik geçmişi, motor becerileri ve hasta yakınlarından alınan bilgiler doğrultusunda teşhis edilebilir. Kesin tanı için ise, verilen ilaçlara olumlu yanıt vermesi beklenir. Tüm bu yöntemler düşünüldüğünde kesin tanının konulması için uzun bir zaman dilimi gereklidir. Hastalığın erken tanısı hastalar için oldukça önemlidir. Çünkü zaman ilerledikçe hastalık sessizce ilerleyebilmektedir. Bu çerçeve içerisinde hastalığın ilerleyişini yavaşlatmak ve hastanın yaşam kalitesini daha da arttırmak hastalığın erken tanısı ile mümkündür.

$\mathrm{Bu}$ çalışmada, erken tanıya destek olmak amacıyla, Parkinson hastalarının tespiti için bilgisayar tabanlı otomatik tespit yöntemleri uygulanmaktadır (Şekil 1). Çalışmada, hastalara ait ses kayıtları kullanılarak hastalığın tespiti yapılmıştır. Literatürde benzer ses kayıtları ile yapılmış çalışmalar vardır [12-14]. Bu çalışmalar göz önünde bulundurularak, elde edilen özniteliklere min-max normalizasyon yöntemi uygulanmış ve karınca koloni algoritması kullanarak öznitelik seçimi yapılmıştır. Destek vektör makinaları algoritması ile Parkinson hastalarının tespit başarımları elde edilmiştir. Çalışmada, hem öznitelik seçiminin performansa etkisi hem de farklı sayıda seçilen özniteliklerin başarımı nasıl değiştirdikleri gözlemlenmiştir. 


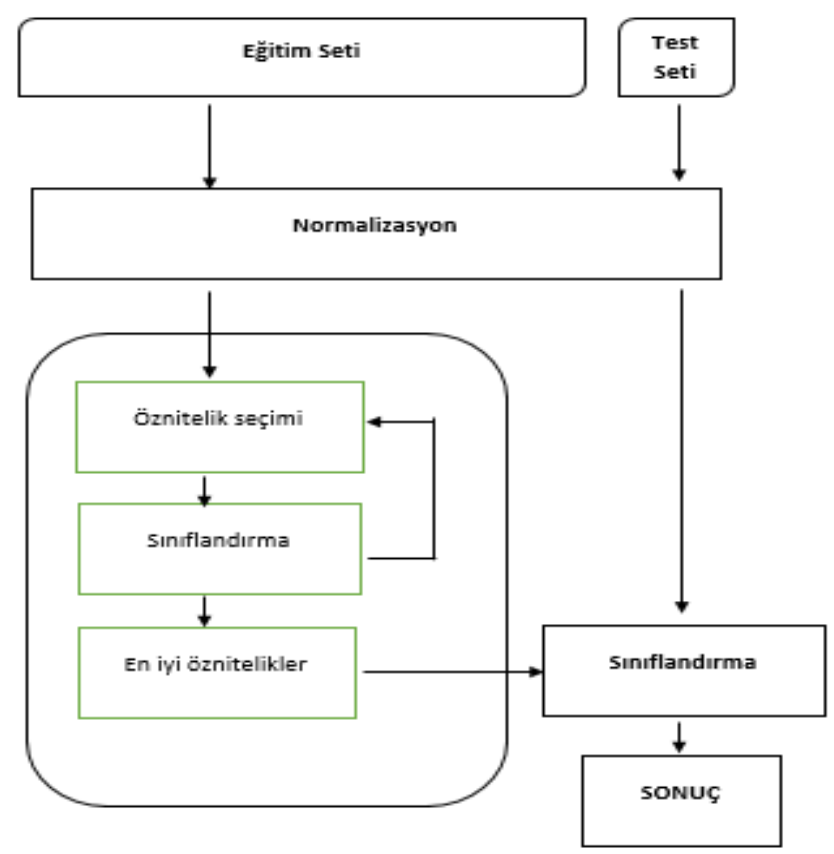

Şekil 1. Amaçlanan sistemin akış diyagramı.

Gelecek başlıklarda, çalışmada kullanılan Parkinson veri seti ve özniteliklerinden, karınca koloni algoritmasindan, Destek vektör makina algoritmasından, min-max normalizasyon yönteminden, başarım ölçütlerinden, deneysel bulgulardan ve son kısımda sonuçlardan detaylı bir şekilde bahsedilmiştir.

\section{MATERYAL VE METOT}

\section{A. PARKINSON VERI SETI}

Çalışmada, UCI veri tabanında herkesin erişimine açık olan Naranjo ve arkadaşlarının kullandıkları veriler ve öznitelikler kullanılmıştır. Veriler, 2019 yılında sisteme sunulmuştur. Bu yönüyle en güncel Parkinson ses verileridir. Naranjo ve arkadaşları verilerle ilgili literatüre iki adet çalışma sunmuşlardır $[12,13]$.

Veri seti, 40 adet, $\% 67,5$ 'i erkek ve $\% 32,5$ 'i kadından oluşan Parkinson hastası ve 40 adet, \%55'i erkek \%45 'i kadından oluşan sağlıklı kişiden alınan verilerden oluşmaktadır. Toplam 80 adet veri üzerinden bir anket ve sürekli / a / seslendirilmesinden elde edilmiş üç kayıt kopyası ile 120 Parkinson ve 120 sağl1klı olmak üzere toplam 240 adet ses kaydı oluşturulmuştur. Tüm veriler Extremadura Üniversitesi Biyoetik Komitesi tarafından onaylanmıştır. Ses verileri üzerinden elde edilen 44 adet öznitelik Tablo 1'de detaylı bir şekilde gösterilmiştir [12, 13]. 
Tablo 1. Ses kayıtları üzerinden elde edilen öznitelikler

\begin{tabular}{|l|l|c|}
\hline Öznitelik & Ölçümler & Adet \\
\hline Adım yerel bozulma ölçümleri & $\begin{array}{l}\text { Göreceli titreşim, mutlak titreşim, göreceli ortalama bozulma } \\
\text { (RAP) ve adım bozulma oranı (PPQ) }\end{array}$ & 4 \\
\hline Genlik bozulma ölçümleri & $\begin{array}{l}\text { Yerel 1şıltı, dB cinsinden 1ş1ldama, 3 noktalı genlik bozulma } \\
\text { katsayı1 (APQ3), 5 noktalı genlik bozulma katsayısı (APQ5) ve } \\
\text { 11 nokta genlik bozulma katsayıs (APQ11). }\end{array}$ & 5 \\
\hline Harmonik-gürültü oranı ölçümleri & $\begin{array}{l}\text { Harmonik-gürültü oranı ölçümleri frekans bantları: 0-500 Hz } \\
\text { (HNR05), 0-1500 Hz (HNR15), 0-2500 Hz (HNR25), 0-3500 Hz } \\
\text { (HNR35), ve 0-3800 Hz (HNR38). }\end{array}$ & 5 \\
\hline $\begin{array}{l}\text { Spektral ölçüm tabanlı Mel frekans } \\
\text { sepstral katsayıları }\end{array}$ & MFCC0, MFCC1, ., MFCC12 & 13 \\
\hline $\begin{array}{l}\text { Mel frekans sepstral katsayılarının } \\
\text { türevi }\end{array}$ & Delta0, Delta1, ., Delta12 & 13 \\
\hline $\begin{array}{l}\text { Nüks (recurrence) periyodu } \\
\text { yoğunluğu entropisi }\end{array}$ & & 1 \\
\hline $\begin{array}{l}\text { Eğimi yok edilmiş dalgalanma } \\
\text { analizi }\end{array}$ & & 1 \\
\hline Pitch periyot entropi ölçümü & & 1 \\
\hline Girtlak-gürültü uyartım oranı & & 1 \\
\hline
\end{tabular}

\section{B. KARINCA KOLONI ALGORITMASI (KKA)}

KKA, Dorigo ve arkadaşlarının karınca sürülerinden esinlenerek ortaya attıkları metasezgisel bir optimizasyon yöntemdir [15]. Gerçek karıncaların herhangi bir besine en kısa yoldan ulaşmaları ve yuvalarına geri dönerken de en kısa yolu tercih etmeleri ve bunu yaparken diğer tüm karınca sürülerini de bu yönde etkilemeleri bu algoritmanın ortaya çıkmasını sağlamıştır. Araştırmalar sonucunda, karıncaların yiyeceğe giderken tercih ettikleri yola kimyasal bir madde olan feromon salgısı bıraktıkları ve böylece birbirleri arasında etkileştikleri için toplu bir şekilde hareket ettikleri ortaya konmuştur. Yuvadan çıkarak yiyecek arayan bir karınca için çok fazla olasılık vardır, fakat ortamdaki feromon madde yoğunluğuna bakarak gideceği yerin en iyi olduğuna karar verir. Burada, en çok feromon maddesi bulunan yolun diğer karıncalar tarafından daha çok tercih edildiği ihtimali ortaya çıkmaktadır. Bu nedenle karıncanın bu yolu tercih etme olasılığı daha da artmaktadır. Bunun yanında karıncaların herhangi bir engel veya alışılmışı dışında bir durumda yeniden, yiyecekle yuvaları arasında en kısa yolu, kısa bir zamanda bulmaları bu yöntemin optimizasyon açısında önemini ortaya koymaktadır. $\mathrm{Bu}$ yöntem ilk olarak gezgin satıcı problemi için uygulanmış ve sonuçların oldukça etkileyici olduğu ifade edilmiştir [16]. KKA öznitelik seçimi işlemlerinde de kullanılmaktadır $[17,18]$. KKA ile öznitelik seçiminde, bir öznitelikğin karıncaların çoğu tarafından seçilmesi, bu özniteliğin diğer özniteliklere göre daha fazla ayırt edici olduğunu gösterir. Sonuç olarak, bu öznitelik daha fazla feromon maddesine sahiptir ve sürüdeki diğer karıncaların da bu özniteliği seçme olasılıkları daha çok olacaktır. Buna göre feromon maddelerinin çokluğuna bakarak ne kadar özniteliğin seçilmesi isteniyorsa seçilebilir. KKA kullanarak öznitelik seçimi adım adım aşağıda verilmiştir.

Başlangıç KKA parametrelerinin girilmesi.

$>$ Özniteliklerin ikilik sistemde ifade edilmesi.

$>$ Karıncaların feromon kimyasalı değerlerine göre öznitelikleri seçmesi (Adım 3) .

$>$ Karıncaların öznitelikler üzerindeki feromon maddelerinin güncellenmesi.

$>$ Seçilen özniteliklerin sınıflandırıcı performanslarının elde edilmesi.

$>$ Seçilen en iyi özniteliklere göre feromon maddesinin tekrardan güncellemesi ve en iyilerinin hafizada tutulması. 
Belirlenen iterasyon değerine kadar en iyi öznitelik kümesinin seçimine devam edilmesi (Adım 3 dönülerek).

\section{DESTEK VEKTÖR MAKİNALARI}

Temel istatistiksel öğrenme teorisine dayanan destek vektör makinaları (DVM), Vapnik ve arkadaşları tarafindan geliștirilmiștir [19]. DVM, sınıflandırma ve regresyon problemlerinde sıklıkla kullanılmaktadır. DVM, veri setinin lineer olarak ayrılabilme ve ayrılamama durumuna göre ikiye ayrılmaktadır. Şekil 2'de lineer olarak ayrılan veri setine ait örnek gösterilmiştir. Lineer olarak ayrılamayan sınıflar için ise çekirdek fonksiyonları kullanılarak sınıflar birbirinden ayrılabilir hale getirilmektedir. Şekil 2‘de DVM sınıflandırıcısına ait genel tanımlar ve parametreler gösterilmiştir. Burada amaç, sınıfları birbirinden ayıran hiper düzlemi bulabilmektir.

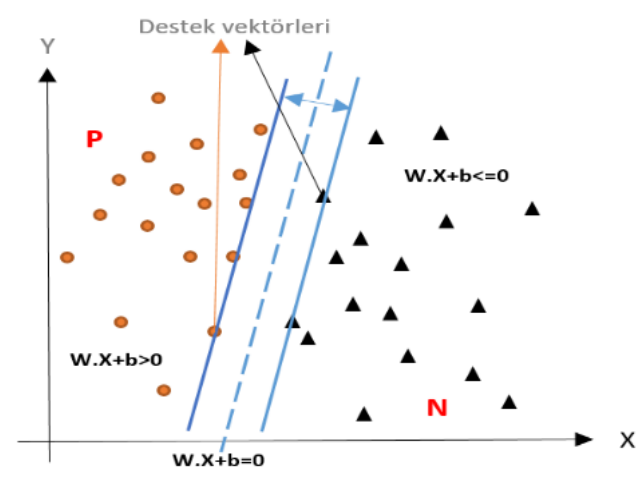

Şekil 2. Destek vektör makinaları

Şekil 2'de gösterildiği gibi hatanın minimum olduğunu destek vektörler belirlenir. Burada, çizilen paralel düzlemin arasındaki uzaklık maksimum olacak şekilde eğitim işlemi tamamlanır. Yeni bir veri seti test için geldiğinde:

$$
\left\{\begin{array}{l}
W_{t} X+b \leq 0 \text { ise Nsinıf } \iota \\
W_{t} X+b>0 \text { ise } P \text { sinıf }
\end{array}\right.
$$

şeklinde sınıflandırılacaktır. $X$ test edilecek veriyi, $W$ ağırlık vektörünü ve $b$ ayar sabitini ifade etmektedir.

Şekil 3 lineer ayrılmayan verilere örnek olarak verilmiştir. Bunlar için çekirdek fonksiyonları kullanılarak veriler doğrusal bir düzleme aktarılır. Doğrusal hale getirilen bu düzlemde sınıflar arası ayrım kolaylıkla gerçekleşir. Bu çalışmada, çekirdek fonksiyonlarından: doğrusal, ikinci dereceden, üçüncü dereceden, ayrıntılı Gauss (fine), orta Gauss (medium) ve kaba Gauss (Coarse) çekirdek fonksiyonları kullanılmıştır. Çalışma, 6 çeşit kernel fonksiyonu ile gerçekleştirilmiştir. 

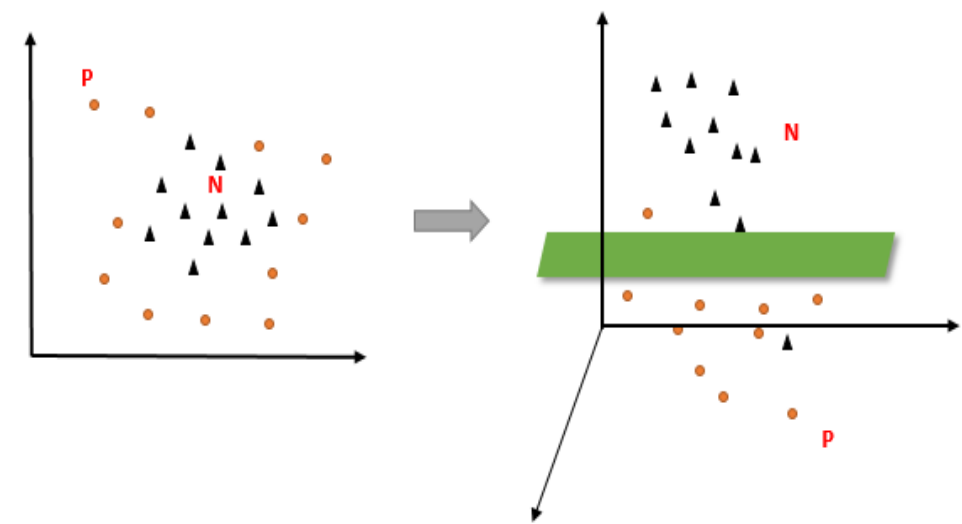

Şekil 3. Lineer ayrılmayan verilerin farklı bir boyuta taşınıp ayrılması

\section{MIN- MAX NORMALIZASYON}

Min-max normalizasyon yönteminde bir özniteliğe ait tüm verilerin en büyük ve en küçük değerleri kullanılarak o öznitelikteki tüm veriler 0-1 arasına indirgenir. Bu işlem tüm öznitelikler için yapılır. Böylece öznitelikler arasındaki farklı aşırı sayısal değerler, 0-1 arasına çekilerek standart hale getirilip, çalışmanın performansları bu şekilde bulunur. Min-max normalizasyon yöntemi:

$$
X_{\min -\max (i)}=\frac{X_{i}-X_{\min }}{X_{\max }-X_{\min }}
$$

şeklindedir. Burada, $X_{\min -\max (i)}$, normalize edilmiş $i$. veriyi, $X_{i}$, normalize edilecek $i$. veriyi, $X_{\min }$, aynı öznitelikteki en küçük değeri, $X_{\max }$, aynı öznitelikteki en büyük değeri ifade etmektedir.

\section{E. BAŞARIM ÖLÇÜTLERI}

Parkinson hastalarının tespitinde kullandığımız ölçütler şu şekildedir [20][21]:

Doğruluk (Accuracy (ACC)): Toplam pozitif ve negatif sınıfa ait olan verilerin ne kadar doğru tespit edildiğinin göstergesidir.

$$
A C C=\frac{T P+T N}{T P+F N+F P+T N}
$$

Duyarlılık (Sensitivity (SEN)): Pozitif sınıfa ait olan verilerin ne ölçüde doğru tespit edildiğinin bir göstergesidir.

$$
S E N=\frac{T P}{T P+F N}
$$

Özgüllük (Specificity (SPE)): Negatif sınıfa ait olan verilerin ne ölçüde doğru tespit edildiğinin bir göstergesidir.

$$
S P E=\frac{T N}{T N+F P}
$$


Hassaslık (Precision (PRE)): Sınıflandırıcıların tespit ettiği pozitif sınıfa ait verilerin ne kadarının geçekten pozitif sınıfa ait olduğunun göstergesidir.

$$
P R E=\frac{T P}{T P+F P}
$$

Formüllerde yer alan TP, Parkinson sınıflı bir verinin sınıflandırıcı tarafindan Parkinson olarak tespit edilmesidir. TN, sağlıklı sınıflı bir verinin sınıflandırıcı tarafından sağlıklı olarak tespit edilmesidir. FP, sağlıklı sınıflı bir verinin sınıflandırıcı tarafından Parkinson olarak tespit edilmesidir ve son olarak FN, Parkinson sınıflı bir verinin sınıflandırıcı tarafından sağlıklı olarak tespit edilmesidir.

Bu çalışmada, Şekil 4'de gösterildiği gibi, eğitim ve test verileri 10-katlı çapraz doğrulama yöntemi ile bölünmüştür. Yöntemde tüm veriler $(\mathrm{k}=10)$ adet parçaya bölünüp, 10 adet parçanın 9 adedi eğitim için kullanılırken 1 adedi test için kullanıldı. Bu işlem $10 \mathrm{kez}$ yinelenip ve ortalama başarımları elde edildi.

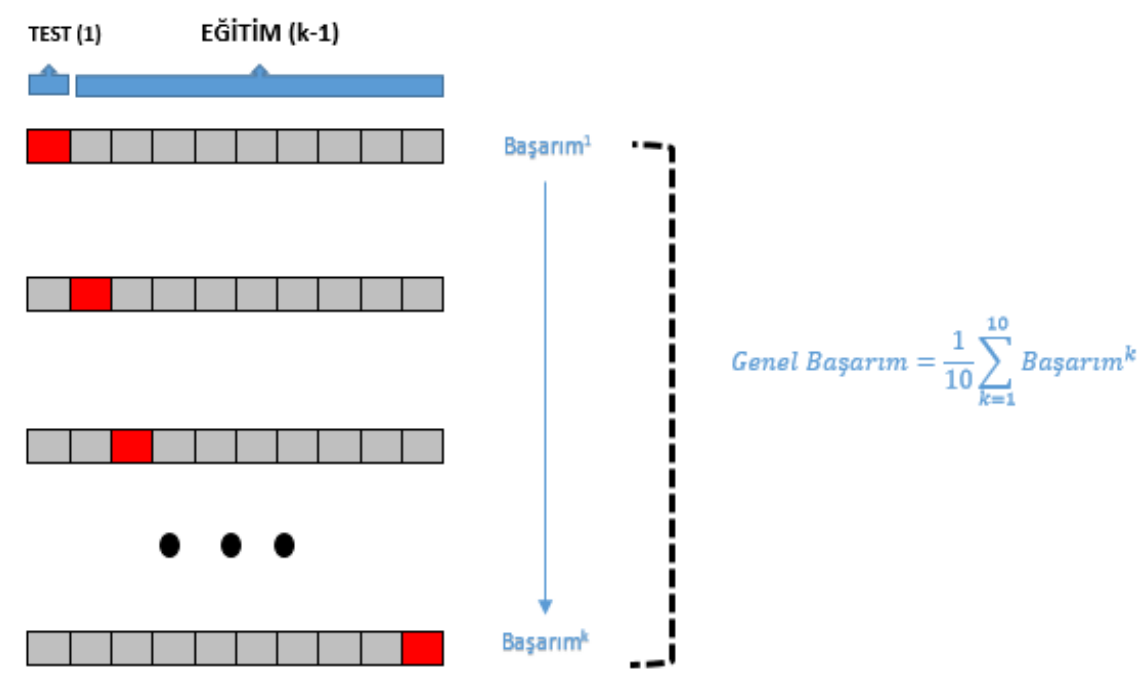

Şekil 4. 10-Katlı çapraz doğrulama yöntemi

\section{DENEYSEL BULGULAR VE TARTISMMA}

Çalışmada, 120 Parkinson hastasına ait ve 120 sağlıklı kişilere ait toplam 240 adet akustik veri kullanılmıştır. Tüm bu veriler üzerinden 44 adet öznitelik çıkarılmıştır. Bu verilerle ve özniteliklerle metasezgisel bir yöntem olan karınca koloni algoritması kullanılarak seçilen özniteliklerin başarımları izlenmiştir. Bununla beraber verilere min-max normalizasyon yönteminin uygulanmasının performansa olan etkileri de araştırılmıştır. Tüm çalışma için MATLAB 2018b paket programı kullanılmıştır.

Eğitim ve test için ayrılan verilerden eğitim süresince elde edilen ortalama karesel hata değerleri Şekil 5'de verilmiştir. Eğriler, 100 iterasyonda, normalizyona tabi tutulmuş ve normalizasyonsuz veriler için elde edilmiştir. 


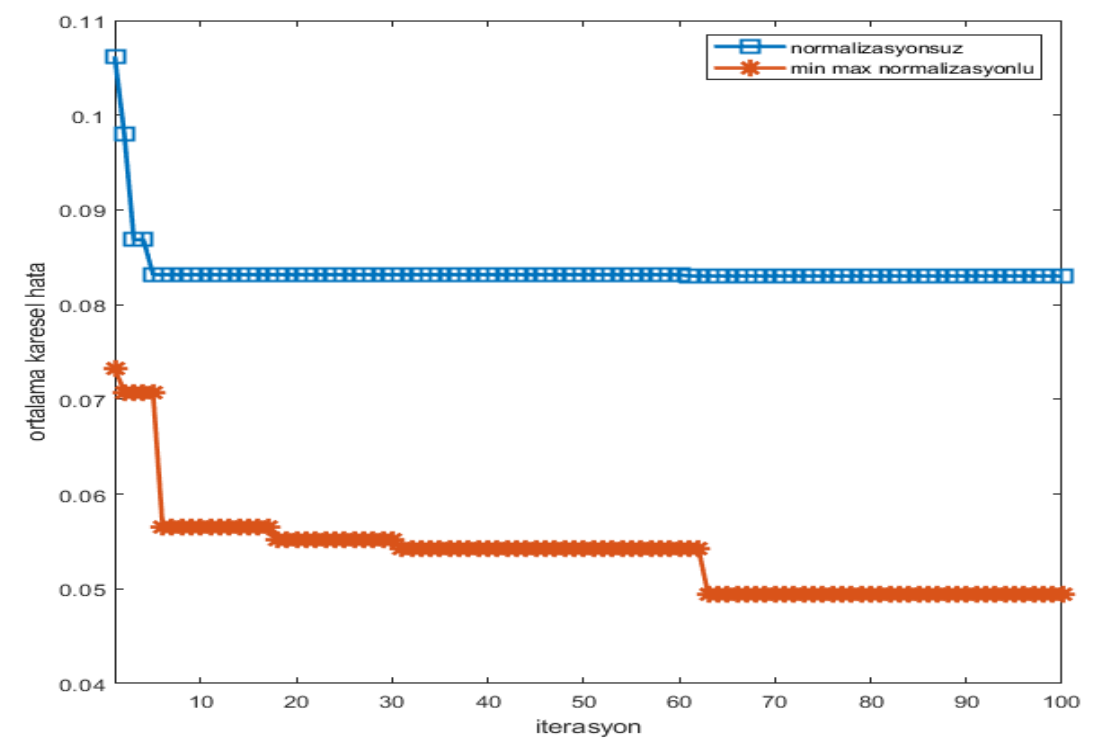

Şekil 5. Eğitim aşamasinda normalizasyonlu ve normalizasyonsuz verilerin ortalama karesel hata değerleri.

Burada, normalizasyonlu veriler için ortalama karasel hata değeri 0,05 değerinin altına düşerken, normalizasyonsuz verilerin ortalama karesel hata değeri 0,08 civarlarında olduğu görülmektedir. Minmax normalizasyon yönteminin uygulandığı verilerin eğitim süresindeki ortalama karesel hata performanslarının daha iyi olduğu görülmektedir.

Şekil 6'da normalize edilmemiş veriler üzerinden seçilen özniteliklere göre (3-5-10-15-20-25-30-3540-Tüm), farklı DVM sınıflandırıcıları için test performans değerleri gösterilmiştir. Sonuçlar ele alındığında en yüksek başarım değeri 30 adet öznitelikte DVM Gauss (medium) ile alındığı görülmektedir.

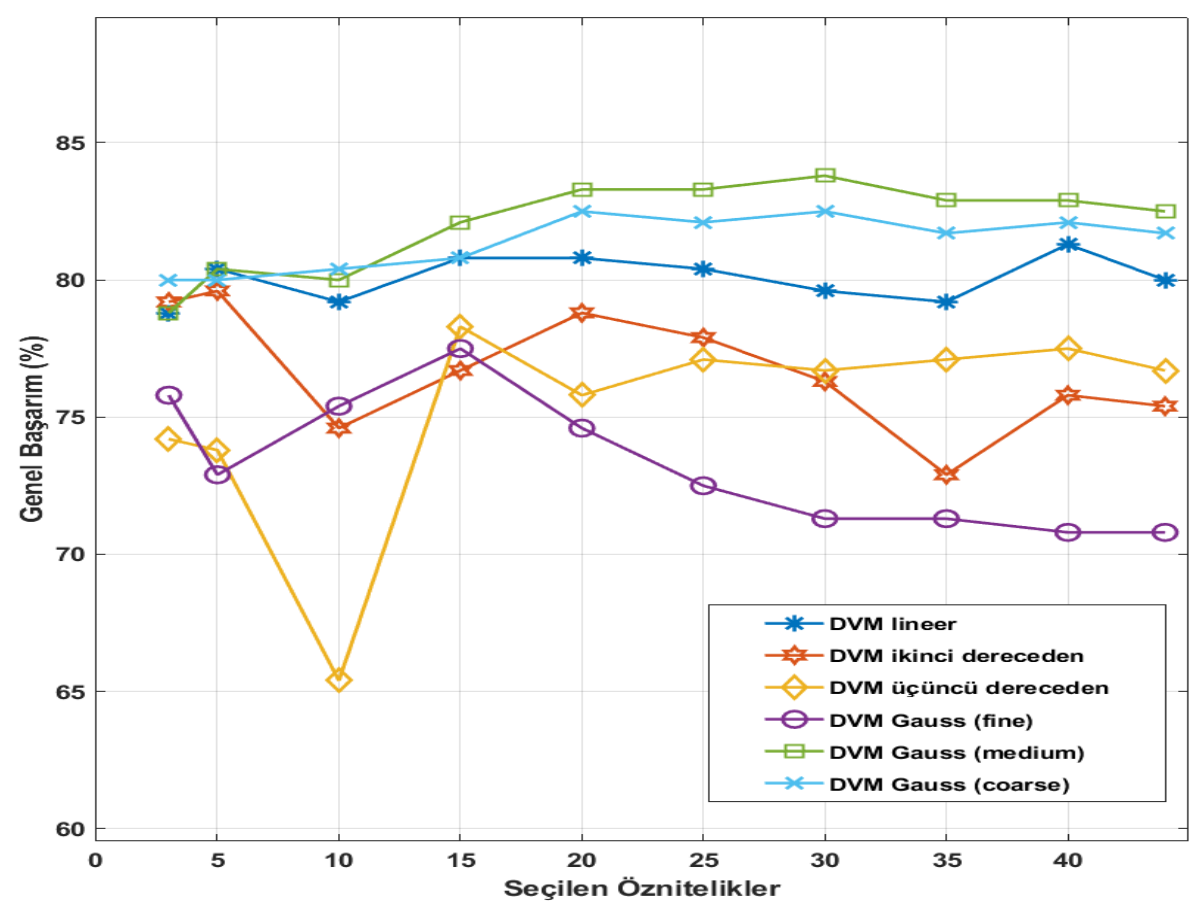

Şekil 6. Normalizasyonsuz verilerin seçilen özniteliklere göre farklı DVM sınıflandırıcıları için test performansları 
Benzer şekilde min-max normalizasyonu uygulanmış veriler için elde edilen farklı öz nitelik değerlerindeki performans sonuçları Şekil 7'de verilmiştir. Şekil 7 incelendiğinde 25 öznitelik ile DVM ikinci dereceden fonksiyon kullanarak elde edilen başarım değerlerinin diğerlerinden daha iyi olduğu görülmektedir.

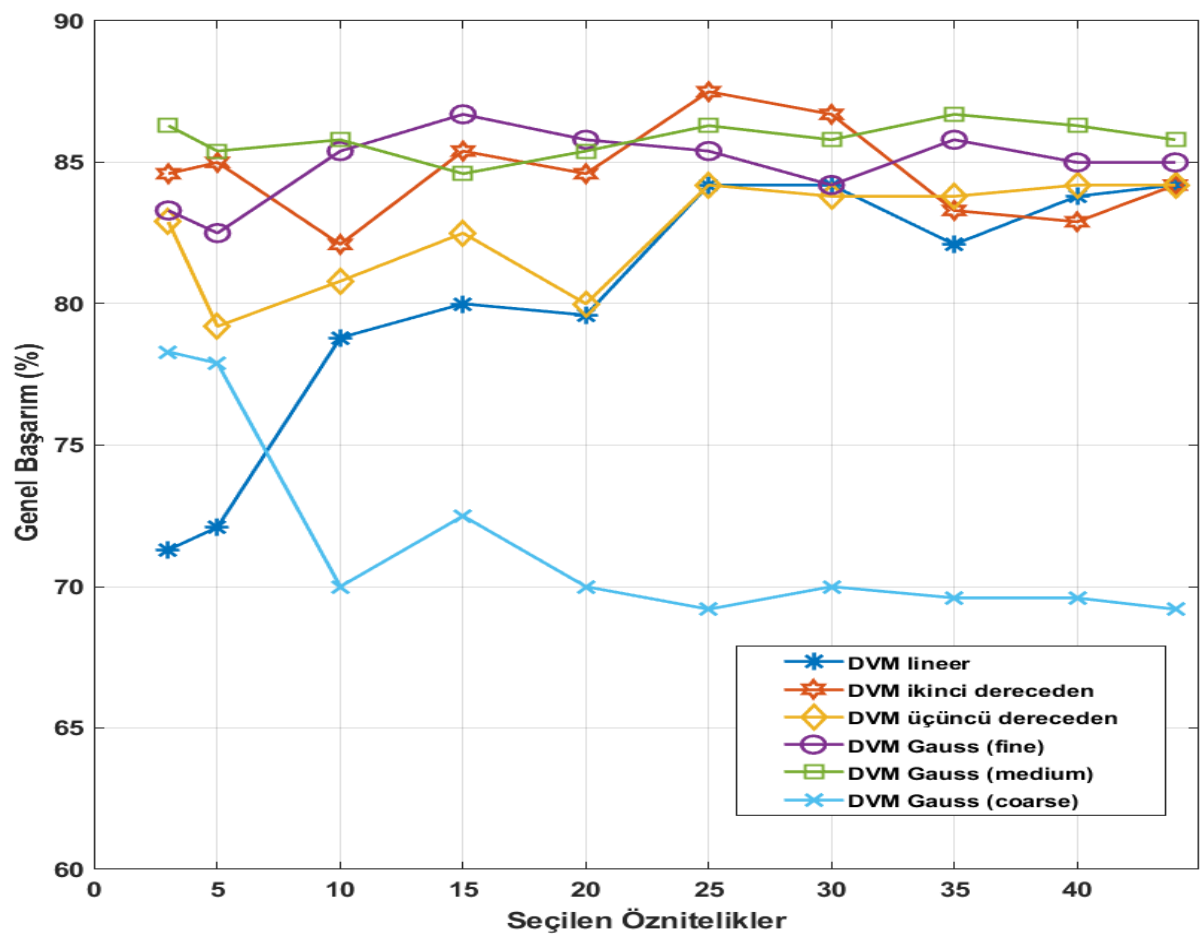

Şekil 7. Normalize edilmiş verilerin seçilen özniteliklere göre farklı DVM sınıflandırıcı için test performansları

Normalize edilmemiş veriler için, elde edilen en yüksek başarıma ait özniteliklerle tüm sınıflandırıcı performansları Tablo 2'de sunulmuştur. DVM Gauss (medium) sinıflandırıcısı ile \%83,3 ACC değeri, \%80,8 SEN değeri, \%86,7 SPE değeri ve \%80,8 PRE değerleri elde edilmiştir. Sınıflandırıcılara göre başarımların oldukça değişkenlik gösterdiği söylenebilir. Dolayısıyla, en iyi sonuç veren sınıflandırıcının tespiti önem arz etmektedir.

Tablo 2. Normalizasyonsuz veriler üzerinden seçilen 30 öznitelik ile sonuçların karşılaştırılması

\begin{tabular}{|l|c|l|l|l|l|l|l|l|l|}
\hline \multicolumn{1}{|c|}{ Algoritma } & $\begin{array}{c}\text { Seçilen } \\
\text { Öznitelik }\end{array}$ & \multicolumn{1}{|c|}{ TP } & TN & FP & FN & $\begin{array}{c}\text { ACC } \\
\text { (\%) }\end{array}$ & $\begin{array}{c}\text { SEN } \\
\text { (\%) }\end{array}$ & $\begin{array}{c}\text { SPE } \\
\text { (\%) }\end{array}$ & $\begin{array}{c}\text { PRE } \\
\text { (\%) }\end{array}$ \\
\hline SVM linear & 30 & 100 & 91 & 29 & 20 & 79,6 & 83,3 & 75,8 & 83,3 \\
\hline SVM Quadratic & 30 & 88 & 95 & 25 & 32 & 76,3 & 73,3 & 79,2 & 73,3 \\
\hline SVM Cubic & 30 & 87 & 97 & 23 & 33 & 76,7 & 72,5 & 80,8 & 72,5 \\
\hline SVM Fine Gaussian & 30 & 58 & 113 & 7 & 62 & 71,3 & 48,3 & 94,2 & 48,3 \\
\hline SVM Medium Gaussian & 30 & 97 & 104 & 16 & 23 & $\mathbf{8 3 , 8}$ & 80,8 & 86,7 & 80,8 \\
\hline SVM Coarse Gaussian & 30 & 100 & 98 & 22 & 20 & 82,5 & 83,3 & 81,7 & 83,3 \\
\hline
\end{tabular}

Min- max yöntemiyle normalize edilmiş veriler ile, KKA kullanarak 25 adet öznitelik kullanılarak elde edilen sınıflandırıcı performansları Tablo 3'de detaylı bir şekilde verilmiştir. Bu tabloda, verilerin normalize edilmesi performansa olumlu yansımıştır. DVM ikinci dereceden fonksiyon ile \%87,5 ACC değeri, \%89,2 SEN değeri, \%85,8 SPE değeri ve \%89,2 PRE değerleri ile en yüksek başarım değerleri 
elde edilmiştir. Parkinson hastası 120 veriden 107 tanesini doğru tespit edebilmişken, 13 tanesini yanlış tespit etmiştir.

Tablo 3. Min-max normalizasyonlu veriler üzerinden seçilen seçilen 25 özntelik ile sonuçların karşılaştırılması.

\begin{tabular}{|l|c|c|c|c|c|c|c|c|c|}
\hline \multicolumn{1}{|c|}{ Algoritma } & $\begin{array}{c}\text { Seçilen } \\
\text { Öznitelik }\end{array}$ & TP & TN & FP & FN & $\begin{array}{c}\text { ACC } \\
\text { (\%) }\end{array}$ & $\begin{array}{c}\text { SEN } \\
\text { (\%) }\end{array}$ & $\begin{array}{c}\text { SPE } \\
\text { (\%) }\end{array}$ & $\begin{array}{c}\text { PRE } \\
\text { (\%) }\end{array}$ \\
\hline SVM linear & 25 & 100 & 102 & 18 & 20 & 84,2 & 83,3 & 85,0 & 83,3 \\
\hline SVM Quadratic & 25 & 107 & 103 & 17 & 13 & $\mathbf{8 7 , 5}$ & 89,2 & 85,8 & 89,2 \\
\hline SVM Cubic & 25 & 103 & 99 & 21 & 17 & 84,2 & 85,8 & 82,5 & 85,8 \\
\hline SVM Fine Gaussian & 25 & 106 & 99 & 21 & 14 & 85,4 & 88,3 & 82,5 & 88,3 \\
\hline SVM Medium Gaussian & 25 & 108 & 99 & 21 & 12 & 86,3 & 90,0 & 82,5 & 90,0 \\
\hline SVM Coarse Gaussian & 25 & 118 & 48 & 72 & 2 & 69,2 & 98,3 & 40,0 & 98,3 \\
\hline
\end{tabular}

Literatürde aynı veri seti ve öznitelikler üzerinden yapılmış çalışmalar Tablo 4'de özetlenmiştir. Naranjo ve arkadaşları bir çalışmalarında, Parkinson hastalarının tespitinde \%85.0 doğruluk değerine ulaşırken [12], öznitelik seçimi yaptıkları bir diğer çalışmalarında \%86.2 doğruluk değerini elde etmişlerdir [11]. Kefeli ve arkadaşları, parçacık sürü optimizasyon yöntemi ve geriye doğru eleme yöntemi ile \%87,0 ACC değerini elde ettiklerinin ifade etmiş̧lerdir. Bu çalışmada sunulan min-max yöntemi ve KKA ile seçilen özniteliklerin literatürdeki diğer tüm çalışmalardan daha yüksek performans değerleri verdiğini söyleyebiliriz.

Tablo 4. Aynı veri seti ile yapılmış çalışmalar.

\begin{tabular}{|l|c|l|c|}
\hline Çalışma & $\begin{array}{l}\text { Öznitelik } \\
\text { Sayısı }\end{array}$ & $\begin{array}{l}\text { Seçim Yöntemi ve } \\
\text { Sinıflandırıcı }\end{array}$ & $\begin{array}{l}\text { Doğruluk(ACC) } \\
(\%)\end{array}$ \\
\hline Naronjo ve ark. [13] & 44 & Bayes tabanlı sınıflandırıcı & 85,0 \\
\hline Naronjo ve ark. [12] & 10 & $\begin{array}{l}\text { Filtre yöntemi, Bayes } \\
\text { tabanlı sınıflandırıcı }\end{array}$ & 86,2 \\
\hline Kefeli ve ark [14] & 18 & $\begin{array}{l}\text { Parçacık sürü optizasyonu, } \\
\text { geriye doğru eleme, destek } \\
\text { vektör makinaları }\end{array}$ & 87,0 \\
\hline Bu çalışma & 25 & $\begin{array}{l}\text { Karınca koloni algoritması, } \\
\text { Normalizasyon, destek } \\
\text { vektör makinaları }\end{array}$ & 87,5 \\
\hline
\end{tabular}

\section{SONUC}

Parkinson, yaşa bağlı olarak artan çok yaygın görülen nörolojik bir hastalıktır. Özellikle yaşı ilerlemiş insanların, yaşlılığın verdiği zorluklara birde bu hastalığın eklenmesi yaşam kalitesi çok fazla düşürmektedir. Bu sebeple, hastalığın erken bir evresin tanı konulması yaşam kalitesini arttırmakla beraber hastalığın kontrol alınmasını sağlayacaktır. Erken tanıya yardımcı olmak amacıyla yapılan bu çalışmada, ses verilerinden elde edilen öznitelikler kullanılarak, KKA ile seçilen özniteliklerin ve minmax normalizasyonunun hastalığın tespitinde oldukça başarılı olduğu gösterilmiştir. Aynı zamanda, aynı veri setini kullanan diğer çalışmalardan da daha yüksek performans değerlerinin elde edildiği gösterilmiştir. Sunulan bu çalışmada kullanılan KKA'nın ve verilerin normalize edilmesi hastalığın tespit oranlarını kayda değer bir şekilde arttırmaktadır. Sunulan bu çalışmanın, klinik uygulamalarda, özellikle Parkinson hastalığının teşhis ve tespitinde, ses verileri kullanılarak doktorlara yardımcı bir araç olarak kullanılabilir olduğunu düşünmekteyiz. 


\section{KAYNAKLAR}

[1] N. J. Maragakis and J. D. Rothstein, "Mechanisms of disease: astrocytes in neurodegenerative disease," Nature Reviews Neurology, vol. 2, no. 12, pp. 679, 2006.

[2] C. A. Artusi, M. Mishra, P. Latimer, J. A. Vizcarra, L. Lopiano, W. Maetzler and A. J. Espay, "Integration of technology-based outcome measures in clinical trials of Parkinson and other neurodegenerative diseases," Parkinsonism \& related disorders, vol. 46, pp. 53-56, 2018.

[3] H. Apaydın and M. Emre, "Parkinson Hastalığında Demans ve Tedavisi," Journal of Neurology, vol. 1, no. 3,pp. 206-212, 2003.

[4] R. Savica, , B. R. Grossardt, W. A. Rocca and J. H. Bower, "Parkinson disease with and without Dementia: a prevalence study and future projections," Movement Disorders, vol. 33, no. 4, pp. 537-543, 2018.

[5] Parkinson Foundation Web Sayfası, https://parkinson.org/Understanding-Parkinsons/Statistics, Erişim tarihi: 02.05.2019.

[6] Parkinsons news today Web Sayfası https://parkinsonsnewstoday.com/parkinsons-disease-statistics/, Erişim tarihi: 01.11.2019.

[7] Türkiye Parkinson Derneği Web Sayfası, http://www.parkinsondernegi.com/menu/5/parkinsonhastaligi, Erişim tarihi: 24.05.2019

[8] Mayo Clinic Web Sayfası https://www.mayoclinic.org/diseases-conditions/parkinsonsdisease/symptoms-causes/syc-20376055, Erişim tarihi: 01.11.2019.

[9] F. S. Juste, F. C. Sassi, J. B. Costa, C. R. F. de Andrade, "Frequency of speech disruptions in Parkinson's Disease and developmental stuttering: A comparison among speech tasks," PloS one, vol. 13, no. 6, 2018.

[10] S. Özekmekçi, H. Apaydın, "Parkinson Hastalığı Hasta ve Yakınları İçin El Kitabı,” 5. baskı, İstanbul, Türkiye: Bayçınar Tıbbi Yayıncılık ve Reklam Hiz. Tic. Ltd. Şti, 1-5, 2013.

[11] W. R. Adams, "High-accuracy detection of early Parkinson's Disease using multiple characteristics of finger movement while typing," PloS one, vol. 12, no.11, 2017.

[12] L. Naranjo, C. J. Pérez, J. Martín, Y. Campos-Roca, “A two-stage variable selection and classification approach for Parkinson's disease detection by using voice recording replications," Computer methods and programs in biomedicine, vol. 142, pp. 147-156, 2017.

[13] L. Naranjo, C. J. Pérez, Y. Campos-Roca, J. Martín. “Addressing voice recording replications for Parkinson's disease detection,” Expert Systems with Applications, vol. 46, pp. 286-292, 2016.

[14] S. Kefeli and A. Narin, " Parkinson hastalarının tespitinde parçacık sürü optimizasyonun performansa etkisi,” 3. International Engineering Research Symposium (INERS'19), Duzce, Turkey, 5-7 September 2019.

[15] M. Dorigo and C. Blum, "Ant colony optimization theory: A survey," Theoretical computer science, vol. 344, no. 2, pp. 243-278, 2005.

[16] M. Dorigo and L. M. Gambardella, "Ant colonies for the travelling salesman problem," Biosystems, vol. 43, no. 2, pp. 73-81, 1997. 
[17] H. R. Kanan, K. Faez, and S. M. Taheri, "Feature selection using ant colony optimization (ACO): a new method and comparative study in the application of face recognition system," In Industrial Conference on Data Mining, (pp. 63-76). Springer, Berlin, Heidelberg. 2007.

[18] M. Deriche, "Feature selection using ant colony optimization," 6th International Multi-Conference on Systems, Signals and Devices, pp. 1-4, 2009.

[19] V. Vapnik. "Statistical Learning Theory,” New York: John Wiley and Sons, 1998.

[20] Y. Isler, A. Narin, M. Ozer, M. Perc, "Multi-stage classification of congestive heart failure based on short-term heart rate variability," Chaos, Solitons \& Fractals, vol. 118,pp. 145-151, 2019.

[21] A. Narin, Y. Isler, M. Ozer, M. Perc, "Early prediction of paroxysmal atrial fibrillation based on shortterm heart rate variability," Physica A, vol. 509,pp. 56-65, 2018. 